\title{
MEMPELAJARI SAINS, MENGIMANI SANG PENCIPTA : Menyisipkan Nilai-Nilai Religius dalam Pembelajaran Sains
}

\author{
Tomo Djudin \\ Pendidikan Fisika, FKIP Universitas Tanjungpura
}

\begin{abstract}
Abstrak
Salah satu nilai yang terkandung dalam sains (IPA) adalah nilai agama (religius). Nilai-nilai ini dapat dikembangkan dengan menyisipkannya dalam pembelajaran suatu topik atau konsep IPA tertentu di sekolah. Pembinaan nilainilai agama ini perlu dipupuk di lingkungan sekolah, salah satunya, untuk menghindari kehampaan spiritual dalam pendidikan sains di sekolah dan dunia ilmiah. Terkait dengan pembinaan nilai-nilai ini, peran guru di sekolah semakin penting di tengah-tengah keterbatasan dan kelangkaan buku-buku teks IPA yang terintegrasi nilai-nilai agama. Menyampaikan kebenaran adalah kewajiban kita semua, apalagi yang datangnya dari Sang Pencipta.
\end{abstract}

Kata kunci : sains, nilai agama, sang pencipta

Bangsa Indonesia adalah bangsa yang religius. Pernyataan ini secara eksplisit (tersurat) dapat diketahui dalam Pembukaan dan pasal 29 ayat 1 UUD 45. Dasr konstitusional ini menjiwai dan dijabarkan dalam semua aspek kehidupan bernegara dan bermasyarakat, termasuk dalam pendidikan. Pendidikan sains (IPA) di Indonesia bertujuan agar siswa memiliki keyakinan keteraturan alam CiptaanNya dan keagungan Tuhan Yang Maha Esa (Depdiknas, 2001:10; Kemendiknas; 2010). Menitipkan tujuan di atas pada pembelajaran sains adalah sungguh rasionaldan tepat. Karena, banyak ayat-ayat Qur'an yang memerintahkan agar kita (manusia) memikirkan sebagian tanda-tanda Kebesaran dan KeagunganNya melalui penciptaan langit dan bumi, juga berbagai fenomena dan peristiwa alam (lihat, misalnya; Q.S : Ali Imran, 3: 190-
191; Nuh, 71: 13-20; An-Naml, 27:70). Selain alasan tersebut, memang sains (IPA) pada hakikatnya adalah suatu tubuh pengetahuan ( $a$ body of knowledge) yang mempelajari, memahami, dan meninvestigasi peristiwa atau fenomena alam (dunia alamiah) dengan segala aspeknya yang bersifat empiris dengan menggunakan metode ilmiah yang mengandung keterampilan proses sains (Harlen, 1985:2-3; Carin, 1997:5).

Ada banyak nilai dalam sains yang dapat dikembangkan ketika kita membantu anak mencobakan proses dan mempelajari konten sains di dalam kelas. Enam diantaranya adalah nilai khusus yang menarik bagi guru: nilai kebenaran, kebebasan, tidak mudah pecaya (skeptisme), keaslian (originality) dalam berpikir dan mengemukakan pendapat, keteraturan, dan komunikasi. Keenam 
nilai ini tidak hanya diperlukan dalam sains, tetapi pada semua bidang (areas) pemahaman manusia lainnya (Abruscato, 1982:6-12). Nilai yang lain yang terkandung dalam sains adalah nilai-nilai agama yang dapat dikembangkan, misalnya dengan menyisipkan ayat-ayat Al-Qur'an (Kauniyah) yang relevan dengan suatu topik atau bahasan tertentu dalam sains (IPA).

Menyinggung masalah pembelajaran berarti membahas pula fungsi dan peranan guru di sekolah (kelas). Hal ini merupakan suatu kewajaran mengingat guru adalah ujung tombak proses pendidikan dan pengajaran di sekolahh. Peran guru dirasakan semakin penting di tengahtengah keterbatasan sarana dan prasarana belajar, misalnya bukubuku teks IPA yang terintegrasi nilainilai agama. Memang mutu pendidikan, hasil belajar siswa, serta perubahan sikap siswa bukan hanya ditentukan oleh guru, melainkan oleh banyak faktor, antara lain mutu masukan (siswa), sarana, dan lingkungan keluarga, faktor-faktor instrumental lainya. Tapi, semua itu pada akhirnya bergantung pada mutu pengajaran, dan mutu pengajaran tergantung pada mutu guru (Dedi Supriadi, 1998:97).

\section{Mengapa Perlu}

\section{Menyisipkan Nilai-nilai}

Agama Dalam Pendidikan

Sains?

Dalam buku teks IPA (Fisika, Biologi, Kimia, Bumi dan Antariksa) yang diterbikan oleh Depdiknas dan Penerbit swasta jarang, bahkan mungkin, tidak dijumpai sentuhansentuhan nilai-nilai agama (ayat-ayat
Al-Qur`an) yang dapat mengantarkan anak untuk mengangungkan ciptaanNya melalui proses pembelajaran. Hal ini wajar karena, mengingat buku-buku yang disusun dan diterbitkan tersebut ditujukan untuk "konsumen" dengan latar agama dan sekolah yang berbedabeda. Akibatnya, nilai-nilai keagamaan yang dapat ditumbuhkembangkan melalui pengajaran IPA di sekolah akan menjadi "kering". Kondisi ini akan semakin diperparah oleh rasa enggan, rasa takut salah, dan merasa tidaak mempunyai tugas atau kewenangan dari pihak guru untuk memberikan penjelasan yang memuat nilai-nilai agama (ayat-ayat Al-Qur`an).

Salah satu upaya untuk menghindari "kehampaan spiritual" dalam pembelajaran IPA, untuk meningkatkan pemahaman siswa tentang konsep-konsep IPA (yang sebenarnya adalah Sunatullah tentang alam semesta, ayat-ayat kauniyah), dan untuk meningkatkan keimanan dan ketaqwaan kwpada sang Pencipta, adalah dengan memberikan makna hukum-hukumfisika berdasarkan nilai-nilai agama yang relevan dengan materi/bahan ajar dan pembelajaran IPA, baik dalam proses pembelajaran di kelas maupun dalam bahan ajar. Dinyatakan bahwa apabila pengajaran IPA diintegrasi dengan pengajaran dan konsep-konsep yang lain, maka kedua akan memperoleh keuntungan, misalnya, menjadikan pengajaran lebih bermakna bagi siswa (Carin, 1997:242) dan akan lebih sesuai dengan kebutuhan siswa Forgarty (1991). Menurut Achmad Baiquni (1997:19), pembinaan nilai-nilai agama dan aqidah (keimanan) ini perlu dipupuk dan dibina di 
lingkungan anak, remaja, dan orang tua.

Sains menurut Islam seharusnya mengandung keajaiban alam yang luar biasa, beserta hukum-hukumnya yang teratur, rapi, dan harmonis. Jadi, selain berperan pemting dalam menghasilkan berbagai tekhnologi dan produknya, sains (IPA) juga berperan sebagai media pengenalan dan objek tafakkur manusia kepada KhalikNya. Perintah untuk mentafakkuri dan merenungkan ciptaan Alla swt di langit dan di bumi banyak ditemukan dan diperintahkan Allah dalam Al-Qur`an. Al-Qur’an mengajak untuk berfikir dengan beragam redaksi (misalnya, tafakkur, tadzakkur, tadabbur) tentang segala hal, kecuali tentang zat Allah swt, karena mencurahkan akal untuk memikirkan Zat-Nya adalah pemborosan energi akal, mengingat pengatahuan tentang zat Allah tidak mungkin dicapai oleh manusia. Maka, manusia cukup memikirkan tentang ciptaan-ciptaan Allah di langit, di bumi, dan dalam diri manusia sendiri (Yusuf Qardhawi, 1998:42). Tafakkur adalah ibadah yang bebas lepas, tidak terikat---kecuali tafakkur tentang Zat Allah ---oleh belenggu apapun, baik faktor ruang dan waktu, tanpa memandang apakah objek tafakkur itu perkara atau hal yang lahir ataupun yang gaib. Tafakkur seorang muslim. Para Ulama sering mengajukan nasihat bahwa apabila seseorang menginginkan perbuatan dan perilakunya tetap baik, ia harus mengawasi berbagai pikiran dan niat dalam hatinya. Selain itu, ia juga hendaknya selalu berzikir kepada Allah swt. serta bertafakkur tentang penciptaan langit dan bumi (Malik Badri, 1996:20).
Jika begitu tinggi kedudukan ibadah Tafakkur tentang ciptaan Allah swt. dalam Islam. Alangkah meruginya orang-orang yang menutup hati, pendengaran, mata, dan mata hati (pikiran)nya terhadap tanda-tanda kekuasaan Allah swt. yang terhampar luas dan jelas di hadapan mata mereka sejak pagi hingga sore hari dan malam hari. Allah berfirman: "Dan banyak sekali tanda-tanda (kekuasaan Allah) di langit dan di bumi yang mereka lalui, sedang mereka berpaling darinya" (Q.S 12:105). Bahkan, sebagian dari orngorang lalai ini mengetahui banyak tanda kekuasaan Allah swt. dalam alam materi tentang energi dan segala yang berkaitan dengan sains, akan tetapi pengetahuan mereka itu hanya terbatas pada segi lahiriah saja, tidak lebih dari itu. Oleh karena itu, alam ciptaan yang indah dan agung ini tidak mampu menghantarkan mereka pada tuhan yang menciptakan dan memeliharanya. Semoga Allah mengampuni kesalahan orang-orang semacam itu, mungkintermasuk kita.

Sains modern dan sistem pedidikan yang mengajarkan sains yang ada sekarang telah mengubah salah satu peran sains yang penting ini. Hal ini dengan mudah dapat kita pahami dari pengalaman kita ketika belajar sains sejak di bangku SD hingga perguruan tinggi. Salah satu permasalahan pengajaran sains di Indonesia adalah kurangnya penyisipan dan kandungan makna, ruh, bahkan perasaan dan akal di dalamnya, sehingga dapat menimbulkan kehampaan spiritual dalam dunia ilmiah (Rahmat Taufiq Hidayat, 2001:22). Ditegaskan oleh Otto Soemarwoto (1991:22) bahwa disadari atau tidak, pemahaman dan 
pengertian manusia (dalam hal ini siswa) tentang alam yang lebih bersifat sekuler dapat menyebabkan manusia (siswa) melihat suatu permasalahan yangterkait dengan alam hanya dari sudut kepentingan manusia saja. Jadi, adalah tugas kita, termasuk guru, untuk membenahi pendidikan sains di sekolah agar para siswa yang mempelajarinya akan terdorong untuk menjadi pribadipribadi yang memahami alam semesta dan mengagungkan Allah dan bertaqwa kepadaNya.

Pemaparan sains dalam bukubuku pelajaran dan penjelasannya oleh guru dan dosensains telah menghilangkan Allah sebagai pencipta (Catur Sriherwanto, 2001:20). Ambil contoh, dalam pelajaran Fisika dipaparkan beberapa teori (misalnya; teori kabut dan Nebula) tentang asal usul tata surya, yang di dalamnya tidak ada satupun yang menyentuh Penyebab dari segala sebab, yaitu Allah Sang Khalik Rabbul Alamin. Belum lagi adanya teori seleksi alam dan evolusi Darwin yang saat ini ternyata diragukan dan bahkan ditolak kebenarannya. Teori tentang asal mula makhluk hidup adalah dari sel atau benda hidup (omne vivum ex ovo) turut mengaburkan pengakuan bahwa Allah lah pencipta semua yang ada di bumi dan di langit. Begitulah sifst teori, ia tidak menghadirkan kebenaran mutlak (absolute) dan bersifat tentatif (sementara).

Kata-kata Allah (Tuhan) atau hal-hal yang berhubungan dengan religius telah hilang dalam wacana sains, sehingga sains telah menjadi indoktrinasi ateisme dan materialisme yang sangat besar pengaruhnya. Bahkan dikalangan ilmuwan Barat pun ada yng mengakui secara jujur fakta ini. Richard C. Lewontin, seorang ahli genetika terkenal dari Universitas Harvard, AS misalnya, berkata: Bukan metode ilmiah dan penemuan-penemuan ilmiah yang mendorong kami menerima penjelasan material tentang dunia yang fenomenal ini. Sebaliknya, kami dipaksa oleh keyakinan apriori kami tehadap prinsip-prinsip material untuk menciptakan perangkat penyelidikan dan konsep-konsep yang menghasilkan penjelasan matrial, betapa pun bertentangan dengan intuisi, atau membingungkan orangorang yang tidak berpengetahuan. Lagi pula, materialisme itu absolut, jadi kami tidak bisa membiarkan Kaki Tuhan masuk (dalam Catur Sriherwanto, 2001: 21). Segala realitas adalah materi dan kehidupan adalah sekedar reasi-reaksi kimia. Kesadaran (emosi dan perasaan) tidak lah lebih dari fenomena yang akan dapat di jelaskan secara fisika dan kimia. Begitu lah sebagian pijakan berpikir menurut paham fisikalisme dan materialisme.

Dalam Al-Qur`an jelas-jelas telah ditegaskan bahwa reaksi alam itu selalu mengikuti aturan-aturan tertentu atau mengikuti sunatullah, kehendak dan aturan-aturan Allah yang telah ditetapkan-Nya pada saat penciptaan dan diikuti oleh alam semesta dengan taat. Alam kelihatannya mempunyai kehendak sendiri, karena ia selalu mengikuti sunatullah yang dikehandaki Sang Maha Pencipta (Achmad Baiquni, 1997:78). Mudah sekali membuktikan dahsyatnya pengaruh ateisme. Unsur "kebetulan" sering dijual untuk mencari konsensus dan persetujuan ilmiah (universally scientific 
agreement)" untuk mengingkari penciptaan makhluk hidup dan alam semesta oleh Tuhan Sang Pencipta. Tanyakan pada diri kita sendiri; Mudahkah kita mengingat Allah ketika mempelajari sains? Apakah sains yang telah kita pelajari membuat kita semakin mengenal bertaqwa kepada Allah?

Dengan sains yang "menolak" Allah ini, tidak heran dapat menyebabkan manusia yang bergelut dengan sains mengalami krisis. Krisis dalam pemikiran maupun ruhani (moral-spiritual) yang ada pada akhirnya terakumulasi secara massal dan muncul dalam bentuk krisis multidemensional, baik dalam skala nasional maupun internasional. Krisis multidemensional yang dampakdampaknya menyusup dan menyentuh setiap aspek kehidupan kita---moral, kesehatan dan kehidupan, kualitas lingkungan, hubungan kemasyarakatan, ekonomi, tekhnologi, dan politik.

Karena sains, pada umumnya, tak dapat dikatakan netral, karena mengandung nilai-nilai yang menyusup melalaui konsensus para pakar yang mengembangkannya, yang sarat dengan nilai kebudayaan mereka, dan karena sains telah lama terlepas dari tantangan umat Islam, maka tidak mengejutkan kita bila Prof. Achmad Baiquni (1997:274) menganjurkan agar "sains diIslamkan". Hal ini tidak berarti bahwa kita harus mengubah rumus-rumus dalam sains itu yang kebenarannya telah terbukti melalalui eksperimentasi; atau mengubah teorinya, melainkan kita harus "memagari" sains agar para siswa tidak terjerumus ke dalam ajaranajaran yang bertantangan dengan agama kita. Jangan sampai nilai-nilai yang tidak Islami dari sains mencemari keimanan dan ketaqwaan serta akidah para siswa. Begitu banyak "bacaan" yang dapat kita pelajari di sekitar kita, baik berupa kejadian atau peristiwa alam atau pengalaman-pengalaman dari kita sendiri atau dari orang lain, atau dari sebuah teori dari berbagai disiplin ilmu yang bisa ditarik untuk dijadikan pelajaran dan peringatan, namun setelah itu kita kita dianjurkan untuk tetap membaca Al-Qur`an, sebagai penyeimbang, agar kita tetap memiliki pegangan (akidah) yang kuat sehingga tidak terjerumus dalam pemikiran-pemikiran yang keliru (Ary Ginanjar Agustian, 2001: 123-124).

Kita yang menerus menekankan kepada para siswa bahwa sains didasarkan pada eksperimentasi dan observasi terhadap alam yamng tampak (empiris) dan tidak mempunyai sekelumitpun pengetahuan tentang alam gaib. Dengan demikian, wajar saja di dalam sains tidak pernah disebut nama (Asma) Allah. Kita harus menjelaskan bahwa sains berkembang melalui berbagai tahapan. Pada tahapantahapan tertentu mungkin saja konsensus dalam sains tidak sesuai, atau bahkan bertentangan dengan isi Al-Qur’an. Akan tetapi karena sains dikembangkan untuk mencari kebenaran, maka pada akhirnya ia akan bersesuaian juga dengan AlQur`an. Sebab, ayat-ayat Allah dalam jagad raya yang diteliti para saintis tidak mungkin bertentangan dengan ayatullah di dalam Al-Qur`an. Jikalau terdapat perbedaan antara pandangan sains dan salah stu ayat Al-Qur`an, maka ada dua kemungkinan. Kemungkinan pertama adalah sains 
masih berada pada tahapan yang sesat pada saat itu karena kurangnya data atau informasi yang bersangkutan kurang benar (Achmad Baiquni, 1997:276). Karena, untuk memahami ayat-ayat Al-Qur'an yang menyangkut alam ini serta prosesproses alamiah di dalamnya, dan yang dinyatakan secara garis besar itu, kita harus mempelajari dan meneliti alam (mempelajari sains).

\section{Penutup}

Kita memang mengakui bahwa sains (IPA) berperan penting dalam menghasilkan tekhnologi dan produknya yang bermanfaat bagi kebutuhan hidup manusia. Akan tetapi, ini bukan stu-satunya peran sains. Sebab, alam semesta selain berfungsi memenuhi kebutuhan hidup, juga berfungsi sebagai ayat (tanda-tanda Kebesaran Allah) yang mengenalkan manusia kepada Pencipta alam semesta tersebut dan beserta sifat-sifat-Nya.

Perlunya menyisipkan nilainilai agama (ayat-ayat kauniyyah) dalam pembelajaran sains (IPA) dapat didasarkan pada beberapa alasan : (1) untuk menghindari kehampaan spiritual dalam pendidikan sains di sekolah dan duniailmiah; Fenomena alam yang ada dan terjadi di bumi dan di langit adalah kajian sains dan sekaligus merupakan objek tafakkur terhadap Allah swt; (3) dengan sains yang "menolak" Allah dapat menyebabkan manusia yang "bergelut" dengan sains mengalami krisis multidemensional; (4) Adanya beberapa pemaparan sains dalam buku-buku pelajaran (teori-teori dan penjelasannya) yanng telah menghilangkan Allah sebagai pencipta; (5) Untuk memahami ayat- ayat Al-Qur'an dinyatakan secara garis besar menyangkut alam ini serta proses-proses alamiah di dalamnya, kita harus mempelajari dan meneliti alam (mempelajari sains); (6) Sebagai upaya untuk "memagari" sains agar para siswa tidak terjerumus ke dalam ajaran-ajaran yang bertentangan dengan akidah dan keimanan agama.

Karena menyampaikan kebenaran adalah kewajiban kita semua, apalagi yang datangnya dari Sang Pencipta, Allah swt., maka ikhtiar kita (guru) menyisipkan berbagai nilai-nilai dan pemaparan agama (ayat kauniyyah) dalam pembelajaran IPA khususnya (dalam lingkungan keluarga), pada pembelajaran mata pelajaran lain, secara ikhlas karena mengharap Ridho-Nya semata, semoga akan bernilai ibadah. Adalah merupakan suatu kewajiban bagi kalangan ilmuwan, sarjana, pelajar,mahasiswa, guru, dan dosen yang ilmunya tentang makhluk ciptaan Allah "memadai" untuk mau berdakwah melalui sains yang dimilikinya. Semoga Allah memberikan Hidayah dan kekuatan kepada kita semua. Amin.

\section{Daftar Pustaka}

Abruscato, J. (1982). Teaching Children Science.

Prientice_Hall,Inc. Englewood Cliffs: New Jersey, USA

Achmad Baiquni. (1997). Al-Qur`an dan Ilmu Pengetahuan Kealaman. Yogyakarta: PT. Dana Bakti Prima Jasa

Anas Abdul Hamid Al-Quz. (1998). Ibnu Qayyim Berbicara Tentang Manusia dan Semesta (alih bahasa oleh Abdul Hakim 
\& Abu Nadia Ahmad). Jakarta: Penerbit Pustaka Azzam.

Ary Ginanjar Agustian. (2001). Rahasia Sukses Membangun Kecerdasan Emosional dan Spiritual ESQ: Emotional Spiritual Quotient. Berdasarkan 6 Rukun Iman dan Rukun Islam. Jakarta: Penerbit Arga.

Carin, R.B. (1997). Teaching Modern Science $\left(7^{\text {th }}\right.$ edition). Merril Prentice Hall: New Jersey, Columbus Ohio, USA.

Catur Sriherwanto. (2001). Membaca Ciptaan, Melupakan Pencipta. Jurnal MQ Pesantren Daarut Tauhid, vol. 1, No.7 (November) : Bandung.

Depdinas. (2001). Kurikulum Berbasis Kompetensi Mata Pelajaran Fisika Sekolah Lanjutan Tingkat Pertama. Pusat Kurikulum Penelitian dan Pengembangan Depdiknas: Jakarta.

Fogarty, R. (1991). The Mindful School. How to Integrate the Curricula. Palatine Skyliht Publishing, Inc : Illionis, USA.

Harlen, W. (1985). The Teaching of Science. Studies in Primary Education. David Fulton Publishers : London.

Mahfuz Sodiq. (2000). Pembelajaran Kimia pada Sub Pokok Bahasan Kajian Pencemaran Lingkungan yang Terintegrasi dengan Nilai-Nilai Agama. Tesis UPI Bandung. Tidak dipublikasikan.

Malik Badri. (1996). Tafakkur Perspektif Psikologi Islam. Remaja Rosdakarya: Bandung.

Moh. Rifa'i. (1997). Al-Qur'an, Terjemahan/Tafsir. CW. Wicaksana: Semarang
Otto Soemarwoto. (1990). Pengembangan Berwawasan Lingkungan. Djambatan: Jakarta.

Riduansyah. (2000). Penerapan Model Pembelajaran Terpadu antara Biologi dan Imtaq untuk Meningkatkan Hasil Belajar Siswa di Aliyah. Tesis UPI Bandung Tidak dipublikasikan.

Rahmat Taufiq Hidayat. (2001). Hari Raya dalam Perspektif Islam. Jurnal MQ Pesanten Daarut Tauhid, vol. 1, No. 8 (Desember): Bandung.

Supriadi, Dedi. (1998). Mengangkat Citra dan Martabat Guru. Adicitra Karya Nusa: Banndung.

Yusuf Qardawi. (1998). Al-Qur'an Berbicara tentang Akal dan Ilmu Pengetahuan. (Alih bahasa Abdul Hayyie Al-Kattani, Lc.). Jakarta : Gema Insani Press. 
15 Jurnal Pendidikan Matematika dan IPA Vol. 3. No. 1. Januari 2012:8-14 